\title{
Ontogeny, diet shifts, and nutrient stoichiometry in fish
}

\author{
Alberto Pilati and Michael J. Vanni \\ A. Pilati and M. J. Vanni (vannimj@muohio.edu), Dept of Zoology, Miami Univ., 212 Pearson Hall, Oxford, OH 45056-1400 \\ USA.
}

\begin{abstract}
Most stoichiometric models do not consider the importance of ontogenetic changes in body nutrient composition and excretion rates. We quantified ontogenetic variation in stoichiometry and diet in gizzard shad, Dorosoma cepedianum, an omnivorous fish with a pronounced ontogenetic diet shift; and zebrafish, Danio rerio, grown in the lab with a constant diet. In both species, body stoichiometry varied considerably along the life cycle. Larval gizzard shad and zebrafish had higher molar C:P and N:P ratios than larger fish. Variation in body nutrient ratios was driven mainly by body $\mathrm{P}$, which increased with size. Gizzard shad body calcium content was highly correlated with $\mathrm{P}$ content, indicating that ontogenetic P variation is associated with bone formation. Similar trends in body stoichiometry of zebrafish, grown under constant diet in the laboratory, suggest that ontogeny (e.g. bone formation) and not diet shift is the main factor affecting fish body stoichiometry in larval and juvenile stages. The N:P ratio of nutrient excretion also varied ontogenetically in gizzard shad, but the decline from larvae to juveniles appears to be largely associated with variation in the N:P of alternative food resources (zooplankton vs detritus) rather than by fish body N:P. Furthermore, the N:P ratio of larval gizzard shad excretion appears to be driven more by the N:P ratio at which individuals allocate nutrients to growth, more so than static body N:P, further illustrating the need to consider ontogenetic variation. Our results thus show that fish exhibit considerable ontogenetic variation in body stoichiometry, driven by an inherent increase in the relative allocation of $\mathrm{P}$ to bones, whereas ontogenetic variation in excretion N:P ratio of gizzard shad is driven more by variation in food N:P than by body N:P.
\end{abstract}

Stoichiometric models in ecology often assume that consumer species are homeostatic with respect to body nutrients (Sterner 1990, Hanson et al. 1997, Schindler and Eby 1997). However, some species show ontogenetic changes in, or at least some variation in, body nutrients, and the consequences of such changes are poorly known. There is evidence that some invertebrates show ontogenetic changes in body stoichiometry, and this variation appears to be affected by growth rates and diet. For example, in copepods Villar-Argaiz et al. (2000) found a gradual decrease in body $\mathrm{P}$ as individuals grew. They also found that the increase of $\mathrm{C}$ and $\mathrm{N}$ with size was affected by growth rate. Hessen (1990) found that juvenile Daphnia magna had more body $\mathrm{P}$ than did adults, probably due to the high growth rate experienced by small bodied organisms (the growth rate hypothesis; Elser et al. 2000). Diet might also have an important effect on the organism's body composition. For example, DeMott et al. (1998, 2004), and DeMott and Pape (2005) demonstrated that $\mathrm{P}$ deficient diets can affect growth rate and body $\mathrm{P}$ content of daphniids. In insects, Frost and Elser (2002) found a negative relationship between body size and body $\mathrm{P}$ content, and this relationship was, as in daphniids, affected by the amount of P in food.

In vertebrates, where diet might also have an important effect in the body elemental composition, there are no studies of ontogenetic body stoichiometry variations. In juveniles, a different diet from the adults tends to maximize growth and survival during the most vulnerable stages of the life cycle. Most studies of diet and diet shifts have been done from an energetics, rather than a stoichiometric, perspective (Bouchard and Bjorndal 2006). To date, only one study analyzed the effect of a diet on the body composition. In a clupeid fish, Deegan (1986) reported a decrease in body N content, and an increase in body $\mathrm{P}$, after it switched its diet from zooplanktivory to detritivory (mainly 
phytodetritus). Also, no studies have linked diet shifts, ontogenetic changes in body composition, and nutrient excretion.

Among aquatic animals, body elemental ontogenetic changes may be particularly important in fish due to bone formation during larval-juvenile development. As vertebrates invest relatively more $\mathrm{P}$ for bone ossification during maturation, whole-body $\mathrm{P}$ content may increase and body N:P ratio may decline, as individuals increase in size (Elser et al. 1996). This relationship between size and changes in body elemental composition was reported for adult fish (Davis and Boyd 1978, Sterner and George 2000) but studies are needed to examine changes in body nutrients over the whole life cycle from larvae to adults, and the consequences of this ontogenetic variation for nutrient cycling.

Fish can be important in nutrient cycling (Vanni 2002), and in some cases excretion by young of the year is particularly important (Kraft 1992). Changes in fish body nutrient content can influence nutrient excretion and recycling to primary producers. In the case of the omnivorous gizzard shad, Dorosoma cepedianum, nutrient excretion by fish supports up to $50 \%$ of summer primary production in productive reservoirs (Vanni et al. 2006a). Gizzard shad often dominates the fish biomass of eastern North America warm-water eutrophic and hypereutrophic lakes, rivers, and reservoirs lower than $45^{\circ}$ latitude (Bremigan and Stein 1999, Vanni et al. 2005). This species undergoes a drastic diet shift when approximately $30 \mathrm{~mm}$ total length (TL). Larval gizzard shad $(<20 \mathrm{~mm})$ feed mainly on zooplankton, while juveniles become facultative detritivores (Yako et al. 1996). In temperate reservoir ecosystems, non-larval gizzard shad rely almost entirely on sediment detritus as a food source, as evidenced by gut analyses and stable isotope analyses (Schaus et al. 2002, Higgins et al. 2006). It is not easy to predict how the N:P ratio excreted by gizzard shad should vary ontogenetically. Larvae likely have a high body N:P compared to adults; all else being equal, stoichiometry theory would thus predict that larvae excrete at a lower N:P than adults. On the other hand, per unit N, larvae need to allocate relatively more $\mathrm{P}$ to growth per unit mass (compared to adults), and larvae feed on zooplankton, which have a higher N:P (composite average of 25:1; Sterner and Elser 2002) than the sediment detritus consumed by adult gizzard shad ( 12:1; Higgins et al. 2006). Ontogenetic differences in food N:P (and perhaps in the relative allocation of $\mathrm{N}$ vs $\mathrm{P}$ to growth) lead to the prediction that larvae excrete at a higher $\mathrm{N}: \mathrm{P}$ than adults.

In this study, we explored variation in body nutrient content during ontogeny, in two fish species, one with and one without an ontogenetic diet shift. We analyzed body nutrient content and excretion rates in gizzard shad, Dorosoma cepedianum, over the course of its ontogenetic diet shift so we could determine how excretion N:P varies ontogenetically. We also analyzed ontogenetic variation in body elemental composition in zebrafish, Danio rerio, grown in the laboratory under a constant diet. This species provides information about the variation in body nutrients in the absence of a diet shift. We also qualitatively compared the apparent influence of diet and bone development on body elemental variations. To our knowledge, this is the first study in which ontogenetic variation in body nutrients is explicitly linked with variation in nutrient excretion, and the first study comparing elemental body composition of species with and without a diet shift.

\section{Methods}

\section{Ontogenetic variation in body nutrient composition of gizzard shad}

We quantified ontogenetic changes in gizzard shad body nutrients and nutrient excretion over the first summer of their life cycle in Acton Lake, a hypereutrophic reservoir located in Butler and Preble Counties, Ohio, where gizzard shad is the most abundant fish species (Schaus et al. 1997, Vanni et al. 2005). Total length (TL) varied from $7 \mathrm{~mm}$ to $135 \mathrm{~mm}$, comprising larvae and young of the year (YOY) juveniles. We assessed the extent to which variation in gizzard shad body stoichiometry is correlated with growth (size) and the diet shift using stable isotope analysis. Furthermore, we measured body calcium to explore the role of bone formation on P stoichiometry. Finally, we incorporated results of previous studies that quantified diets, body nutrients and excretion rates of adult gizzard shad in Acton Lake (Schaus et al. 1997, 2002, Schaus 1998, Higgins et al. 2006) to produce a complete picture of the ontogeny of nutrient stoichiometry in this species.

In summer 2003, we sampled gizzard shad by following the cohort for the whole growing season (June to September) in Acton Lake. Small larvae (7 to $20 \mathrm{~mm}$ ) were sampled with an ichthyoplankton net with $500 \mu \mathrm{m}$ mesh. Small young-of-the-year (YOY) $(20$ to $55 \mathrm{~mm}$ ) were sampled with an ichthyoplankton net with $4 \mathrm{~mm}$ mesh. YOY $>55 \mathrm{~mm}$ were collected with an electroshocker. All fish were sorted into size classes of $5 \mathrm{~mm}$ for individuals $<50 \mathrm{~mm}$ and $10 \mathrm{~mm}$ for individuals $>50 \mathrm{~mm}$. This sorting resulted in more detailed information for larvae and juveniles undergoing the diet shift (which usually occurs at sizes of 20$40 \mathrm{~mm}$ ) than for fish after the diet shift. For the smallest size classes, we pooled up to 30 individuals in each replicate to get enough tissue for nutrient content analysis ( $\mathrm{C}, \mathrm{N}$ and $\mathrm{P}$ ). For size classes larger than $30 \mathrm{~mm}$, we used only one individual per sample and we 
analyzed 1-3 replicates (most often 2) per sampling date. To explore the interannual stoichiometric variability, this sampling protocol was repeated during the summer of 2004 but less intensively. We did not sample individuals beyond their first year of life because prior studies provide data on both body nutrients and excretion rates of these size classes in Acton Lake (Schaus et al. 1997, Higgins et al. 2006).

Fish of all size classes were placed immediately on ice and taken to the lab where they were measured, gutted, and dried at $60^{\circ} \mathrm{C}$ until a constant weight was obtained. Depending on fish size, the whole fish was ground to a powder using either a mortar and pestle or an ultracentrifugal grinding mill. Body $\mathrm{C}$ and $\mathrm{N}$ contents were obtained with a $\mathrm{CHN}$ analyzer, and $\mathrm{P}$ content was measured with an autoanalyzer following digestion of tissue with $\mathrm{HCl}$ (Higgins et al. 2006). Stable isotopes were measured with an isotope ratio mass spectrometer coupled with an elemental analyzer. An average of two replicate fish samples were analyzed per date, and only one analytical replicate was obtained from each stable isotope sample. We also took two zooplankton samples for isotope analysis during the period shad rely exclusively on zooplankton (July 2003). One sample included the whole zooplankton community on a GF/F filter, while the other one was comprised of only calanoids (the most abundant and the most preferred prey item by the larvae at the time, A. Pilati unpubl.). Sediment isotope data were obtained from Schaus (1998) and Schaus et al. (2002), and we found no need to run more samples due to the observed small variability in $\delta^{15} \mathrm{~N}$ and $\delta^{13} \mathrm{C}$ in these previous studies. For whole body $\mathrm{Ca}$ analysis, the samples were ashed in a muffle furnace at $550^{\circ} \mathrm{C}$ for $6 \mathrm{~h}$. The ashes were dissolved with concentrated nitric acid, and then diluted with deionized water to reach a concentration of $\sim 1 \% \mathrm{HNO}_{3}$. Ca data were obtained by emission spectroscopy.

\section{Ontogenetic variation in body nutrient composition of zebrafish}

To gain insight into the importance of a diet shift on the ontogeny of fish stoichiometry, we compared temporal changes in the body nutrients of gizzard shad caught in the wild with those of zebrafish reared in the laboratory with a constant diet following protocols by Westerfield (2000) and Matthews et al. (2002). We kept $\sim 20$ individuals per $100 \mathrm{ml}$ during embryonic stage, $400 \mathrm{ml}$ during the larval period or 31 during the juvenile stage. Larvae and juveniles were maintained in continuous flow through aquaria kept at $28^{\circ} \mathrm{C}$. Zebrafish reached $30 \mathrm{~mm}$ total length in 7 months. The diet consisted of dried brine shrimp, Artemia sp. $\left(\delta^{15} \mathrm{~N}\right.$ : $-0.87 \% \pm 0.69$ ), ground to edible sizes. Fish were fed three times a day during larval stages and once a day during adult stages. Zebrafish samples were processed following the same methodology as for gizzard shad, but Ca was not analyzed due to the small mass of tissue available.

\section{Ontogenetic variation in nutrient excretion by gizzard shad}

Stoichiometry models predict that variation in both body nutrients and diet can lead to significant variation in nutrient excretion rates or ratios (Sterner 1990, Elser and Urabe 1999). To assess these potential links, during June and July of 2005 we measured excretion rates of larval and juvenile gizzard shad collected from Acton Lake. Detailed description of the procedure is found elsewhere (Schaus et al. 1997, Higgins et al. 2006). Briefly, gizzard shad were collected with ichthyoplankton nets, and immediately transferred to acid-washed beakers containing $15-50 \mathrm{ml}$ (depending on fish size) of pre-filtered lake water $(0.7 \mu \mathrm{m}$ pore glass fiber filters). For larvae smaller than $10 \mathrm{~mm}$, we used $1-3$ fish per container (so that enough nutrients were excreted for analysis), but for larger sizes we used only one individual per container. Beakers were kept at epilimnetic temperatures for approximately $15 \mathrm{~min}$. Water samples (before the addition of fish and after the incubation) were filtered using a glass fiber filter, preserved with sulfuric acid, and analyzed for ammonia and soluble reactive phosphorus with a autoanalyzer. To standardize N:P excretion ratio with fish size, we calculated the mass-specific excretion rate. For this purpose the length of each fish was used to estimate mass using the following formula: mass $(\mathrm{g})=0.0035 \times$ length $(\mathrm{cm})^{3.3749}$ (A. Pilati unpubl.).

\section{Stoichiometric analyses of gizzard shad N:P excretion ratio}

To explicitly examine the potential roles of body N:P and food N:P in driving excretion $\mathrm{N}: \mathrm{P}$ ratios, we applied the Sterner (1990) stoichiometry model to larval and adult gizzard shad. This model uses three variables to predict the excreted N:P ratio: the N:P of the consumer's body, the N:P of the consumer's food, and the maximum gross growth efficiency $\left(\mathrm{GGE}_{\max }\right)$ for the nutrient most likely to limit growth (in this case P). For the "body" N:P, usually the consumer's whole body N:P at a particular instant in time is used as the predictor. However, larval gizzard shad body $\mathrm{P}$ increases greatly as individuals grow (Results); thus larvae need to allocate more $\mathrm{P}$ towards growth (per unit $\mathrm{N}$ allocated) than would be the case if body $\mathrm{P}$ remained constant over time. This could lead to lower $\mathrm{P}$ excretion rates (hence higher excretion $\mathrm{N}: \mathrm{P}$ ) compared to individuals 
maintaining constant body N:P. Thus, we hypothesized that we could better explain ontogenetic variation in excretion N:P if we used the observed allocation of $\mathrm{N}$ and $\mathrm{P}$ to growth (rather than viewing body $\mathrm{N}$ and $\mathrm{P}$ as homeostatic commodities) as a predictor of $\mathrm{N}: \mathrm{P}$ excretion ratio. We calculated $\mathrm{N}$ and $\mathrm{P}$ allocated to new growth using data on body nutrient contents and daily growth rates for the 2003 cohort (A. Pilati unpubl.). Then, we obtained the N:P ratio of this growth allocation (hereafter "allocated N:P").

Thus, we applied Sterner's (1990) model to larval shad $(<20 \mathrm{~mm})$, using two scenarios. Under one scenario, the consumer's whole-body N:P was used as the "body N:P." In the other scenario, the allocated $\mathrm{N}: \mathrm{P}$ to new growth was used as "body N:P". For adults we used only whole-body N:P because body N:P does not change with additional growth (Results). $\mathrm{GGE}_{\max }$ values (for $\mathrm{P}$ ) are not known, so we initially used a $\mathrm{GGE}_{\max }$ of 0.71 (Torres and Vanni 2007), which is similar to $\mathrm{GGE}_{\max }$ for reported by Schindler and Eby (1997) for several fish species. Then, for adults we adjusted the $\mathrm{GGE}_{\max }$ until the excreted N:P ratio estimated by the model corresponded with that measured in the field, to generate the range of feasible values for $\mathrm{GGE}_{\max }$.

\section{Statistical analysis}

To compare the elemental composition and ratios of the 2003 and 2004 gizzard shad cohorts, we used analysis of covariance (ANCOVA) (proc glm, SAS ver. 9.1), with body nutrient contents and ratios as the dependent variables, cohort as the categorical variable, and size (total length) as a covariate. Inspection of the body nutrient and ratio data showed that these parameters did not vary linearly with fish size over the entire first year. Rather, nutrient contents and ratios changed more during the early stages of growth and then remained relatively constant. Therefore, we split the data series using a threshold value of $40 \mathrm{~mm}$ to ensure linearity below and above that threshold. Then, separate ANCOVAs were run for each portion of the data.

To compare trends in elements and ratios between gizzard shad and zebrafish, we ran ANCOVAs after standardizing body size and nutrient content/ratio variables. As the range in absolute body size and elemental composition is different for these two species (gizzard shad attain much larger adult size; Fig. 1), we transformed fish size to percent maximum reported size, and element or ratio as percent of maximum observed value, to bring all variables to comparable scales. We then used ANCOVA to compare species, using species as the categorical variable.

\section{Results}

\section{Gizzard shad body nutrients}

Gizzard shad body C, P and $\mathrm{N}$ varied considerably throughout development. Percent $\mathrm{C}$ decreased until a threshold size of $\sim 40 \mathrm{~mm}$ (fish $<40 \mathrm{~mm}$ includes all larvae and smaller juvenile YOY) and then slowly increased with size (Fig. 1A); variation with size was similar in 2003 and 2004. Body P content increased three-fold from the smallest larvae to YOY of around $40 \mathrm{~mm}$, then remained relatively constant with growth (Fig. 1B). The increase in \% $\mathrm{P}$ observed in individuals $<40 \mathrm{~mm}$ was similar between cohorts. After reaching $40 \mathrm{~mm}$, the 2004 cohort had higher \% P than the 2003 cohort, but within each cohort $\mathrm{P}$ content remained quite constant with size (Fig. 1B). Percent $\mathrm{N}$ on the other hand, did not seem to have a clear threshold, and it decreased gradually and almost linearly with fish size in both cohorts (Fig. 1C).

Elemental ratios of shad bodies also varied along the life cycle, and this variation seemed to be strongly driven by P. C:P decreased with size until $\sim 40 \mathrm{~mm}$, after which it remained constant (Fig. 1D). N:P also decreased drastically during larval and early juvenile stages $(<40 \mathrm{~mm})$ after which it continued decreasing but at a much lower rate (Fig. 1E). The stoichiometry of individuals smaller than $40 \mathrm{~mm}$ differed between cohorts, as individuals from 2004 had statistically lower C:P and N:P than individuals from 2003. C:N ratio on the other hand, decreased slightly with size during larval stages and then increased slightly in larger individuals (Fig. 1F). These trends in body C:N were similar for both cohorts. Variation in body C:N was much less pronounced than that in C:P or N:P (Fig. 1). Overall, elemental ratios differed greatly for larvae and YOY; larval shad $(<20 \mathrm{~mm})$ C:N:P was 110:25:1 while YOY juveniles $(>20 \mathrm{~mm})$ had a ratio of 40:9:1.

The striking change in $\mathrm{C}, \mathrm{P}, \mathrm{C}: \mathrm{P}$ and $\mathrm{N}: \mathrm{P}$ that takes place before gizzard shad reach a size of $40 \mathrm{~mm}$ could be the result of the diet shift from zooplanktivory to detritivory. The diet shift that takes place when gizzard shad leave larval stages is evident from stable isotope data (Fig. 2). The $\delta^{13} \mathrm{C}$ increased from $-28.94 \%$ $(\mathrm{SD} \pm 1.49)$ in larvae to $-26.23 \%(\mathrm{SD} \pm 0.56)$ in juveniles, corresponding to the difference in $\delta^{13} \mathrm{C}$ of zooplankton ( -29.5 ; this study) and low density sediment detritus ( $\sim 26.5$; from Smoot 1999$)$. The increase in $\delta^{13} \mathrm{C}$ was similar in both years (Fig. 2B). The $\delta^{15} \mathrm{~N}$ also increased with gizzard shad size (Fig. 2A). In 2003 larval shad had a $\delta^{15} \mathrm{~N}$ of $11.6 \% \pm 0.80$ and juvenile shad had a $\delta^{15} \mathrm{~N}$ of $13.9 \% \pm 0.88$. The $\delta^{15} \mathrm{~N}$ values of larval shad were $\sim 3.5 \%$ above those of zooplankton, suggesting a typical one trophic level enrichment. However, the $\delta^{15} \mathrm{~N}$ values of juvenile, 


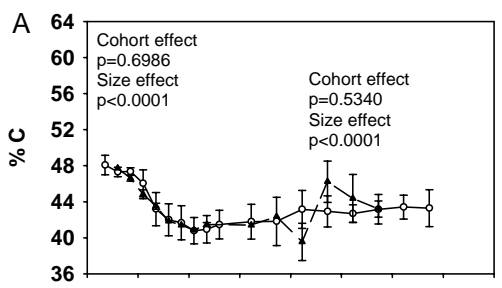

G
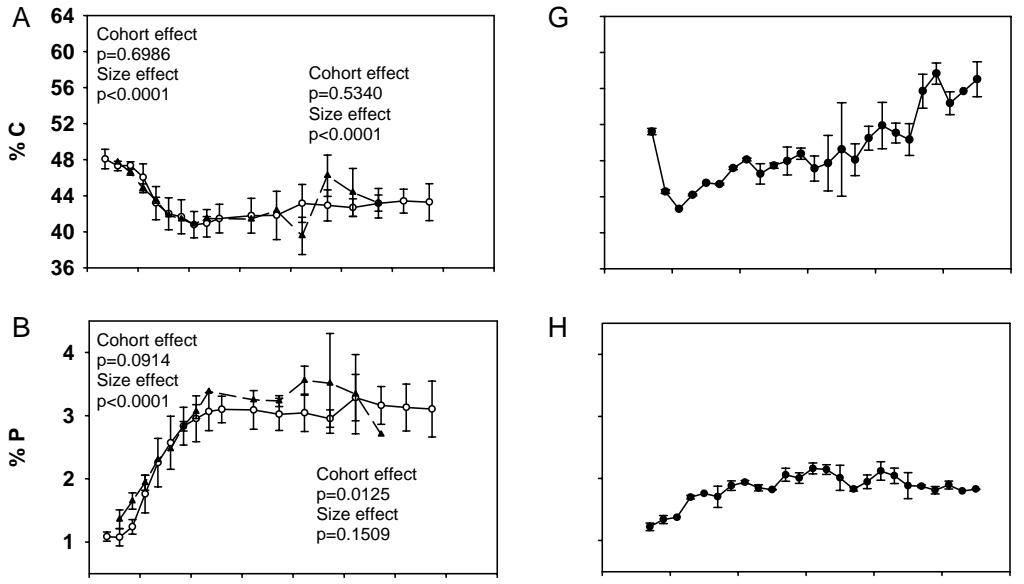

$\mathrm{H}$
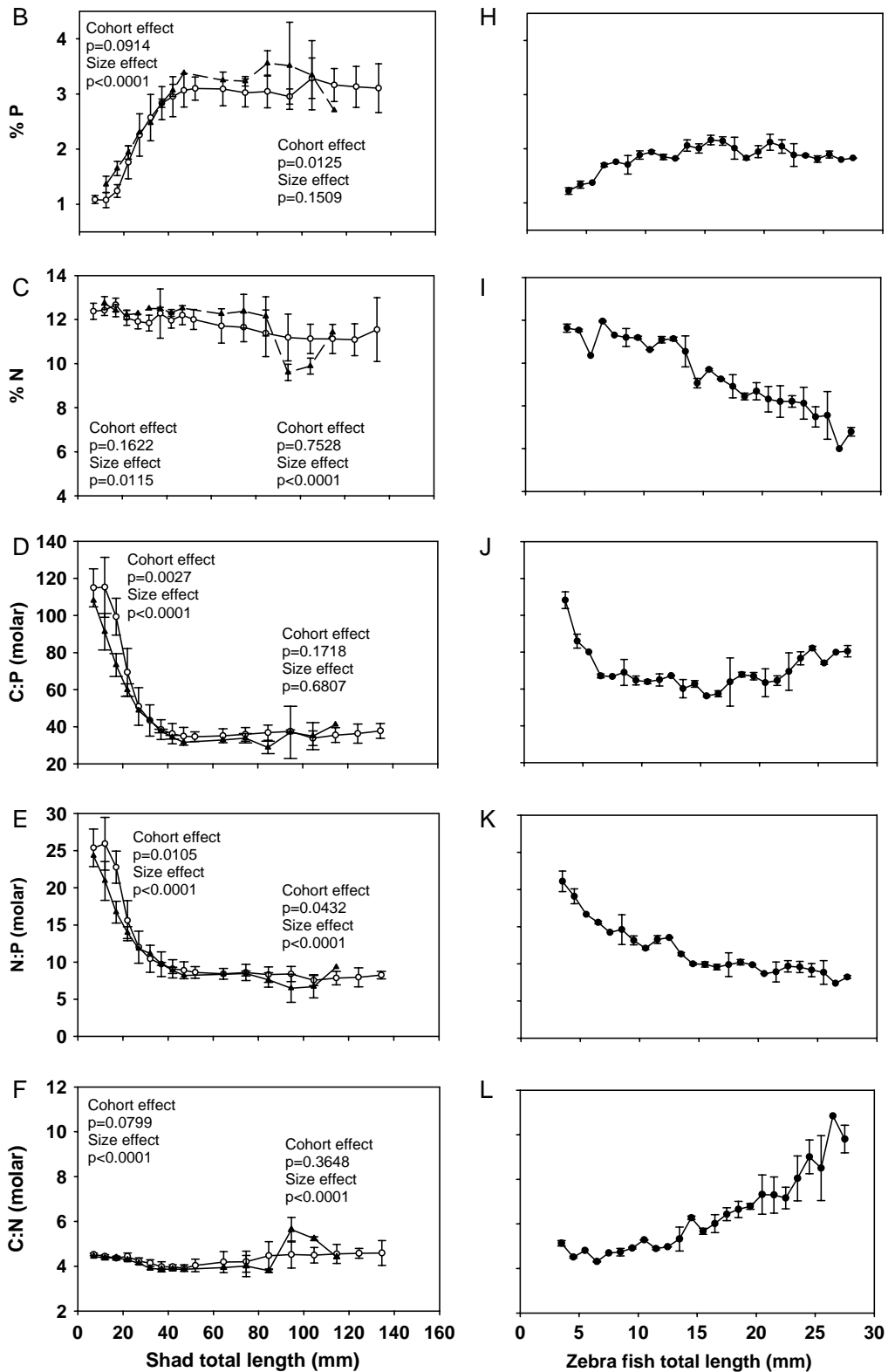

Fig. 1. Ontogenetic changes in percent C (A, G), P (B, H), N (C, I), and molar C:P (D, J), N:P (E, K) and C:N (F, L) ratios for gizzard shad, Dorosoma cepedianum, from Acton Lake and for zebrafish, Danio rerio, raised in laboratory with no diet shift. For gizzard shad two different cohorts are depicted (open circles $=2003$, closed circles $=2004$ ). All values are expressed as the mean $( \pm$ SD). ANCOVA examined the differences between the 2003 and 2004 cohort of gizzard shad (categorical variable) and the effect of size (covariate). The data set was divided at a threshold body length value of $40 \mathrm{~mm}$ to ensure linearity of data below (data on the left) and above (data on the right) that threshold (Methods). 

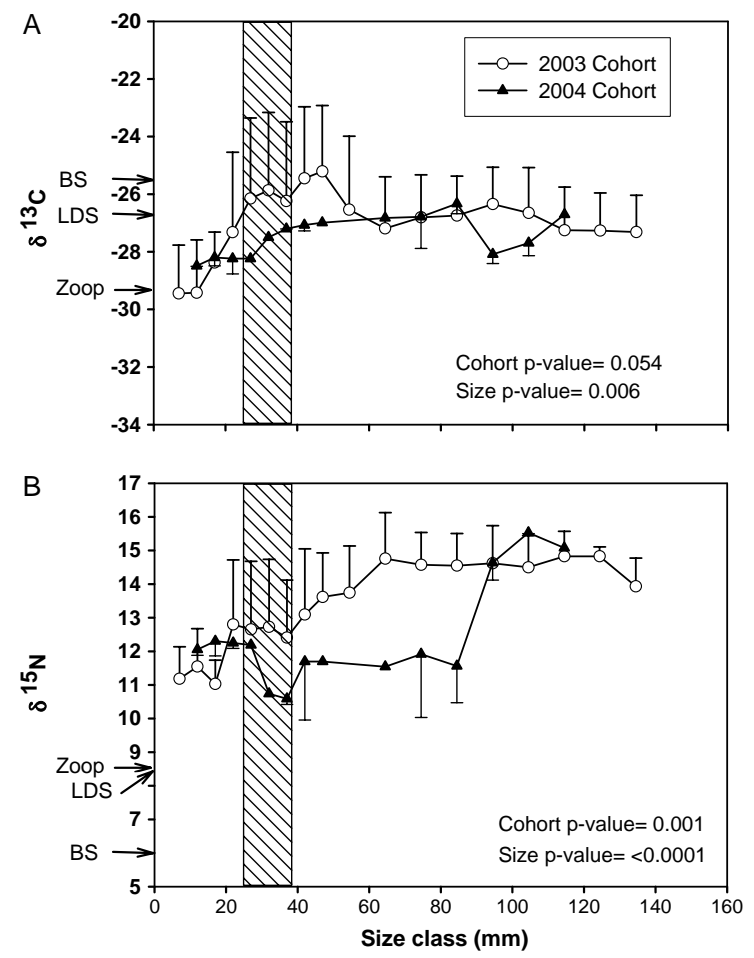

Fig. 2. Stable isotope variation with size for two different gizzard shad cohorts (open circles $=2003$, closed triangles $=$ 2004). (A) $\delta^{13}$ C. (B) $\delta^{15} \mathrm{~N}$. Values are expressed as the mean $( \pm S D)$. The shaded bar represents the diet shift. To the left of the bar $(<25 \mathrm{~mm})$, gizzard shad are exclusively zooplanktivorous (Dettmers and Stein 1992), and to the right $(>38$ $\mathrm{mm}$ ) detritivorous (Mundahl and Wissing 1987, 1988). The arrows represent the isotopic values of zooplankton (Zoop) (this study), low density sediments (LDS) (Smoot 1999) and bulk sediments (BS) (Schaus 1998) from Acton Lake.

sediment-feeding shad were much higher than sediment detritus (equivalent to two trophic levels of enrichment).

Whole-body $\mathrm{Ca}$ also changed ontogenetically. Like $P$, it increased during larval and early juvenile stages until a threshold of $\sim 40 \mathrm{~mm}$ TL after which it remained relatively constant (Fig. 3A). Body $\mathrm{Ca}$ and P were highly correlated (Fig. 3B), but some of total body P $(0.75 \%$ of dry mass; i.e. the intercept in Fig. $3 \mathrm{~B})$ was not associated with $\mathrm{Ca}$. The average Ca:P ratio (molar) for shad larval stages $(6-20 \mathrm{~mm})$ and for YOY $(>20 \mathrm{~mm})$ was $0.41(\mathrm{SD}= \pm 0.15)$ and $1.02(\mathrm{SD}=$ $\pm 0.09)$ respectively.

\section{Zebrafish body nutrients}

To further explore the relationship between diet and ontogenetic P changes, we analyzed ontogenetic element and molar ratio variation in zebrafish under a
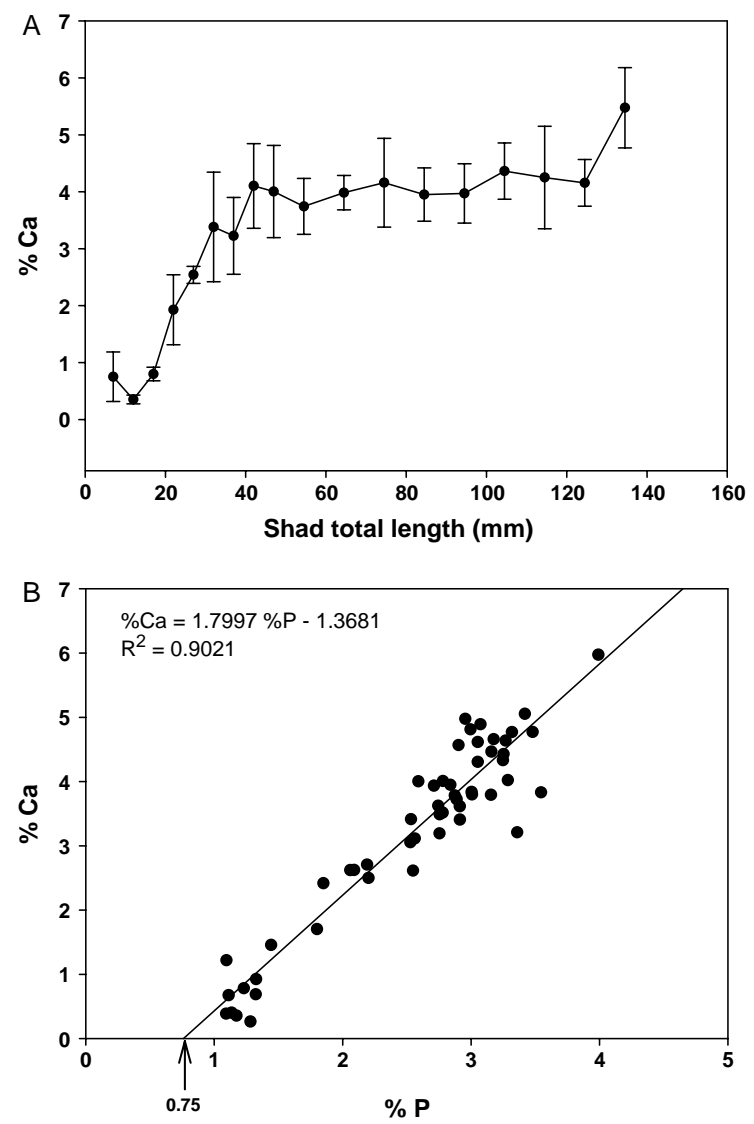

Fig. 3. (A) Ontogenetic variation in percent $\mathrm{Ca}$ for gizzard shad collected from Acton Lake in 2003. Mean \pm SD. (B) Relationship between $\mathrm{Ca}$ and $\mathrm{P}$ in gizzard shad.

constant diet. All zebrafish stages had a similar $\delta^{15} \mathrm{~N}$ signature $(2.73 \%$ o \pm 0.45$)$ which was $3.6 \%$ higher than the food source $(-0.87 \% \pm 0.49)$, indicating successful growth under the same diet. Under these conditions zebrafish\% C decreased initially until $6 \mathrm{~mm}$ TL and increased afterwards (Fig. 1G). P variation, though not as broad as in gizzard shad, increased until $10 \mathrm{~mm}$ TL and then remained quite constant (Fig. 1H). Percent N (Fig. 1I) decreased linearly with fish size. Of the three molar ratios, C:P was the only one that showed a clear threshold at around $6 \mathrm{~mm}$ TL (Fig. 1J), but, as for P, variation was not as broad as the variation observed for gizzard shad C:P. N:P (Fig. 1K) decreased and C:N (Fig. 1L) increased with size. Even though some of the trends in zebrafish appeared to be similar to those in gizzard shad, an ANCOVA showed significant differences between species when using standardized body size and body nutrient contents/ratios ( $\mathrm{P}$-values not shown). Larval zebrafish $(<8 \mathrm{~mm})$ had a C:N:P molar ratio of 82:18:1 while YOY $(>8 \mathrm{~mm})$ had a ratio of 67:10:1. 


\section{Gizzard shad nutrient excretion}

The ratio at which gizzard shad excreted $\mathrm{N}$ and $\mathrm{P}$ (hereafter, excretion $\mathrm{N}: \mathrm{P}$ ) varied substantially along the life cycle (Fig. 4). When we compared the excretion results from this study with those from Schaus et al. (1997), Higgins et al. (2006) and Torres and Vanni (2007) for larger Acton Lake gizzard shad, we found that larvae $(6-20 \mathrm{~mm})$ had a higher and more variable excretion N:P ratio $(35.28 \pm 23.75$ molar $)$ than juveniles $(20-50 \mathrm{~mm})(12.49 \pm 5.04)$ and adults $(>50 \mathrm{~mm})(18.02 \pm 7.41)$. There was a strong decline in excretion $\mathrm{N}: \mathrm{P}$ in individuals smaller than $50 \mathrm{~mm}$ TL (see inset in Fig. 4) but excretion N:P seemed to be lower and more constant in larger individuals.

\section{Discussion}

\section{Ontogenetic variation in body nutrients}

Body elemental composition of both gizzard shad and zebrafish clearly vary along the life cycle. For example, $\mathrm{C}$ in gizzard shad decreased during larval and early juvenile stages and then remained quite constant thereafter. The $\mathrm{C}$ decline in early life stages (Fig. 1A) could be associated with both abiotic (water temperature) and biotic factors (food quality and growth). Pierce et al. (1980) observed a lipid decline in age-0 gizzard shad towards mid summer, and hypothesized that high water temperature increased metabolic rates and reduced fat storage. They also speculated that lower food quality might be affecting $\mathrm{C}$ decline, as sediment energy content declined $6.5 \times$ towards the middle of the summer. In our study, the decline observed during

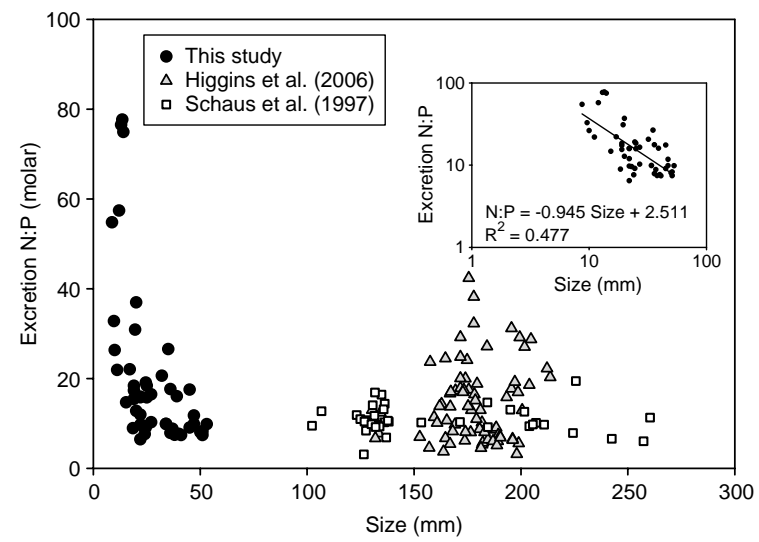

Fig. 4. Ontogenetic variation in excretion N:P of gizzard shad from Acton Lake. Closed circles correspond to larval and juveniles stages (this study), open squares and gray triangles correspond to adults from Schaus et al. (1997) and Higgins et al. (2006) respectively. The inset shows the log-log graph for individuals smaller than $50 \mathrm{~mm}$ (this study). the diet shift might be affected by the reduction in food quality from zooplankton to detritus. Zooplankton are $\sim 50 \%$ C by dry weight (Hessen and Lyche 1991) while lake sediments are only $\sim 2 \%$ organic $\mathrm{C}$ by dry weight (Higgins et al. 2006). Although gizzard shad are capable of feeding on sediment detritus that is higher in $\mathrm{C}$ and nutrients than ambient sediments, ingested detritus has an organic $\mathrm{C}$ content of only $\sim 8 \%$ by dry weight in Acton Lake (Mundahl and Wissing 1988, Higgins et al. 2006). High growth rates observed in gizzard shad $<40 \mathrm{~mm}$ (Mundahl and Wissing 1987, Schaus 1998) could have also influenced this variation in carbon, as the pre-existing $\mathrm{C}$ in fat could have been diluted by other new mass (bones, muscle). Also, high growth rate in smaller, fast-growing individuals could have resulted in less allocation of $\mathrm{C}$ to fat tissues as opposed to the high fat storage observed in larger (age-1 and age-2 fish), slow-growing gizzard shad (Pierce et al. 1980).

Gizzard shad P content, on the other hand, increased sharply during larval and early YOY stages. It was as low as $1 \% \mathrm{P}$ of dry mass - i.e. similar to $\mathrm{P}$ content in many invertebrates - in larval stages and as high as $3.47 \%$ for larger YOY (Fig. 1B). In our study, once shad reached $\sim 40 \mathrm{~mm}$, body $\mathrm{P}$ remained relatively constant, and was similar to that of adult shad in Acton Lake (3.2\% of dry mass; Higgins et al. 2006). To our knowledge, variation in body $\mathrm{P}$ from larval to adult stages has been examined in only one other fish species (Deegan 1986). The relative increase $(>3 \times)$ we observed for gizzard shad is greater than that observed for this species, a marine clupeid in which body P increased from 2.27 to 2.97\% from larvae to juveniles (Deegan 1986). Davis and Boyd (1978) also found an increase in centrarchid\%P with size, although these authors did not include larval stages in their analysis. However, in other species, body $\mathrm{P}$ does not increase with size, or increases only weakly, among non-larval size classes (Goodyear and Boyd 1972, Sterner and George 2000). Further studies are needed to determine to what extent different fish species vary ontogenetically in body nutrients from larval through adult stages.

Body N:P ratios also do not remain constant along the life cycle for either the gizzard shad or the zebrafish. Larvae of both species had higher N:P than juveniles (i.e. N:P ratio decreased with fish size). The decrease in body $\mathrm{N}: \mathrm{P}$ ratio (Fig. $1 \mathrm{E}, 1 \mathrm{~K}$ ) follows a pattern that is virtually opposite that of $\mathrm{P}$ (Fig. $1 \mathrm{~B}, 1 \mathrm{H})$ suggesting that $\mathrm{P}$ content, and probably bone formation, is responsible for this trend. As expected, we found that allocated N:P was lower than whole-body N:P for smaller larvae (Fig. 6A), reflecting the need for small larvae to sequester relatively much P. Eventually, when whole-body $\mathrm{P}$ was no longer changing, allocated $\mathrm{N}: \mathrm{P}$ and whole-body N:P converged (Fig. 6A). However, allocated N:P declined with size, following the same 
ontogenetic pattern as that for whole-body N:P. Gizzard shad and zebrafish had an N:P ratio of $\sim 25: 1$ and 18:1, respectively, during larval stages and leveled off at $\sim 10: 1$ at larger stages. Our results corroborate the prediction made by Elser et al. (1996) who estimated that a small vertebrate would have a ratio of 24:1 while a large vertebrate would have a ratio of $\sim 10: 1$.

Body C:P ratio decreased with size (Fig. 1D, 1J). This trend is particularly strong in gizzard shad during early juvenile stages, while in zebrafish C:P declined sharply for small fish (as in shad) but then increased in larger fish. Thus, for zebrafish the lowest C:P ratio was found at intermediate sizes. This U-shaped trend is affected by higher $\mathrm{C}$ content observed in larger zebrafish (Fig. 1G). When studying the stoichiometry of other cyprinid fishes, Sterner and George (2000) found that $\% \mathrm{C}$ was positively related with fish size, but these authors did not analyze larval and early juvenile stages.

Stable isotopes of both $\mathrm{C}$ and $\mathrm{N}$ increased with gizzard shad size, and similar patterns were observed by Schaus (1998) and Schaus et al. (2002). The diet shift indicated by $\delta^{13} \mathrm{C}$ analysis when shad leave larval stages has already been corroborated by previous stomach content analysis (Mundahl and Wissing 1987, Shepherd and Mills 1996, Yako et al. 1996), and earlier studies with stable isotopes (Schaus et al. 2002). Larval shad had a similar $\delta^{13} \mathrm{C}$ to zooplankton of Acton Lake, while post-larval shad had a similar $\delta^{13} \mathrm{C}$ to low-density sediments of this lake (arrows in Fig. 2A).

${ }^{15} \mathrm{~N}$ data also suggest a diet shift, although trends are more complicated than those for ${ }^{13} \mathrm{C}$. When larval gizzard shad $\left(\delta^{15} \mathrm{~N}=11.6\right)$ are compared to their food source (zooplankton), there is an isotopic enrichment of $3.1 \%$, an enrichment level similar to what one would expect for one trophic level (Fig. 2B). However, once they switch their diet to sediments there is an increase in $\delta^{15} \mathrm{~N}$ of the equivalent of almost two trophic levels over the sediments. Other studies in Acton, and two other reservoirs, also show that detritivorous shad have $\delta^{15} \mathrm{~N}$ levels that are much higher $(8-10 \%)$ than ambient sediments (Sigler 2002). The apparently greatly elevated $\delta^{15} \mathrm{~N}$ levels of detritivorous shad may be at least partially explained by selective feeding. As mentioned above, Acton Lake gizzard shad feed preferentially on low density sediments, which are relatively rich in organic matter (including microbes) and have a $\delta^{15} \mathrm{~N}$ of $\sim 8.5 \%$ (Smoot 1999) (Fig. 2B). Thus, when juveniles are compared to low density sediments, the isotopic $\mathrm{N}$ enrichment is $5.4 \%$. While this enrichment is still higher than that typically observed between trophic levels $(\sim 3.4 \%),{ }^{15} \mathrm{~N}$ trophic enrichment for a single trophic transfer can range from 2 to $5 \%$ oo (Post 2002) and the use of $3.4 \%$ may only be robust when applied to entire food webs with many species and many trophic links. Although some uncertainty remains in terms of the mechanisms of ${ }^{15} \mathrm{~N}$ enrichment, particularly in detritivores, the important point is that the ontogenetic increase in $\delta^{15} \mathrm{~N}$ that we observed in this study corresponds to a diet shift from zooplankton to sediment detritus.

Is the $\mathrm{P}$ increase in shad due to a diet shift or simply due to ossification of bones? The diet shift occurred at the same time as changes in elemental body composition, but for a shorter period of time, so it apparently does not drive changes in body elemental composition. Body C, P, C:P and N:P stabilized at $\sim 40 \mathrm{~mm} \mathrm{TL}$, while diets had shifted from zooplankton to sediments (according to our $\delta^{13} \mathrm{C}$ analysis as well as prior studies in other years) by $25 \mathrm{~mm}$. Furthermore, if $\mathrm{P}$ variation was associated with a diet shift, gizzard shad (with a diet shift) and zebrafish (without a diet shift) would show different trends, which does not seem to be the case. Even though the increase in P for zebrafish is not as pronounced as that of gizzard shad and the two species are statistically different, both species show a clear increase in P content until a threshold value $(40 \mathrm{~mm}$ in shad and $10 \mathrm{~mm}$ in zebrafish), and then relatively constant body $\mathrm{P}$ above this size (Fig. $1 \mathrm{~B}, 1 \mathrm{H}$ ). If $\mathrm{P}$ variation is associated with bone formation, the mass of bony structures (i.e. scales and bones) should vary in concert with body P. Unfortunately, it is almost impossible to estimate the amount of bone in fish, especially in larval stages. Nevertheless, bone is formed mainly by hydroxyapatite, which has a Ca:P molar ratio of 2.16:1 (Sterner and Elser 2002). Love (1980) cited two studies where $\mathrm{Ca}$ allocated to bones in two species of fish - one marine and one freshwater - varied from $79-95 \%$ of total body Ca. Therefore, if we assume that almost all $\mathrm{Ca}$ is associated with bones, and $\mathrm{Ca}$ and $\mathrm{P}$ in shad are highly correlated, $\mathrm{P}$ variations would be mainly associated with bone development, even though this species (a clupeid) is not as bony as other taxa such as cyprinids or percids. However, not all $\mathrm{P}$ appears to be related to bone as shown in Fig. 3B. Whole body Ca:P in shad (1.02 for juveniles) was almost half that of bone (hydroxyapatite, 2.16). A considerable amount of $\mathrm{P}$ that is therefore not associated with bone, especially in larval stages. For example, small larvae have $\sim 1 \% \mathrm{P}$ in their bodies, of which $\sim 0.75 \%$ is not associated with $\mathrm{Ca}$ (intercept in Fig. 3). Furthermore, if we consider that the average \% P for all individuals studied is $2.6 \%$, of which $0.75 \%$ is not associated with $\mathrm{Ca}$, this indicates that as much as $71 \%$ of the total $\mathrm{P}$ is associated with bone (Ca). Consequently, bone formation can explain much of the ontogenetic variation in $\mathrm{P}, \mathrm{C}: \mathrm{P}$ and $\mathrm{N}: \mathrm{P}$, which seems to be the case in this study.

If the wide ontogenetic $\mathrm{P}$ variation observed in gizzard shad and zebrafish also occurs in other fish species, stoichiometric models would need to be more expansive and better consider the dynamic nature of 
fish C:N:P ratios. Taxonomic identity, especially familial affiliation, is thought to have an important effect on $\mathrm{P}$ variation. Fish in bone rich families, like Percidae and Centrarchidae (Sterner and George 2000), and Loricadidae (Vanni et al. 2002), tend have higher P content. In this research, we show that if larval and post larval stages are considered, the variation within a species can be as great as that among taxa. For example, gizzard shad larval and early juvenile stages had comparable variation in body $\mathrm{P}$ to the reported values for 52 fish species in 24 other families (Fig. 5). Within the family Clupeidae, for example, Deegan's study (1986) suggests that the marine species Brevoortia patronus had similar body $\mathrm{P}$ as shad when considering only juveniles and subadults. However, among larvae, shad had much lower P. So, by comparing just nonlarval stages, it would seem that these two species in the same family have very similar body $\mathrm{P}$, but when considering larvae, the familial pattern does not hold. Granted, the values plotted in Fig. 5 for other species are means and thus do not reflect intraspecific variation within a study; nevertheless it is clear that by considering all life stages, variation in gizzard shad body $\mathrm{P}$ is substantial relative to variation among species. Similarly, the ontogenetic variation in zebrafish overlapped with 11 reported species belonging to eight other families. Finally, the ontogenetic variation of bluegill

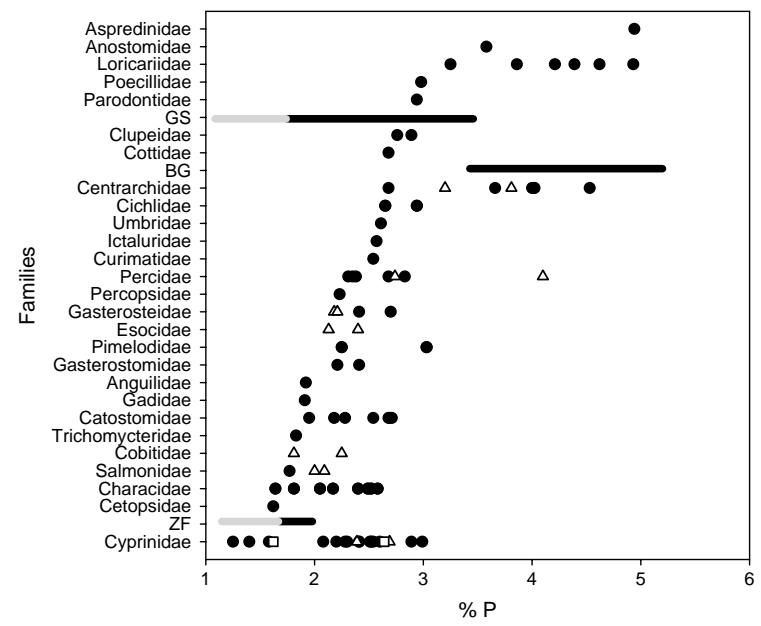

Fig. 5. $\mathrm{P}$ variation for different freshwater fish families. Family data are adapted from Goodyear and Boyd (1972), Davis and Boyd (1978), Penczak (1985), Penczak et al. (1985), Sterner and George (2000), Tanner et al. (2000) and Vanni et al. (2002). Each dot represents different species for the different families. Open triangles and open squares within the same family represent information for the same species from two different studies. The ontogenetic $\mathrm{P}$ variation is depicted with grey lines for larval states and black lines for juveniles and adults. Gizzard shad (GS) and zebrafish (ZF) P variation is from this study, while bluegill data $(B G)$ are adapted from Davis and Boyd (1978). shown by Davis and Boyd (1978) was similar to the variation observed by other studies in that family (Centrarchidae), even though their study did not include individuals $<2.5 \mathrm{~cm}$. In this case, the bluegill $P$ variation overlapped only with eight other species that correspond to four other families. Therefore, our findings would indicate that the inclusion of larval stages in the analysis can blur taxonomic (familial) differences.

\section{Ontogenetic variation in nutrient excretion ratios}

Stoichiometric theory predicts that, all else being equal and under homeostatic conditions, body N:P and excretion N:P should be negatively correlated. Thus, an increase in excretion N:P should occur with increasing body size in gizzard shad, because body $\mathrm{N}: \mathrm{P}$ decreases with age until individuals are $\sim 40 \mathrm{~mm}$. However, this clearly was not the case: larvae had both higher body N:P and excretion N:P than juveniles and adults (Fig. 1E, 4). This suggests that food N:P might have a strong effect on excretion stoichiometry. Larval gizzard shad are zooplanktivorous, selecting mainly rotifers, nauplii, and adult copepods (M. Gonzalez unpubl.), while juveniles and adults feed mainly on lake sediment detritus (Mundahl and Wissing 1987, 1988, Schaus et al. 1998, Higgins et al. 2006); the detritus consumed by shad has a low $\mathrm{N}: \mathrm{P}(\sim 12$ molar; Higgins et al. 2006). These results suggest that ontogenetic variation in excretion $\mathrm{N}: \mathrm{P}$ may be controlled more by variation in food $\mathrm{N}: \mathrm{P}$ than by body $\mathrm{N}: \mathrm{P}$.

To explore this possibility further we applied the Sterner (1990) homeostatic model to larvae (using both whole-body N:P and allocated N:P, as described in Methods) and adults (using only whole-body N:P because body $\mathrm{N}: \mathrm{P}$ does not vary with size in adults). Specifically, we used a "body" N:P of 24.68 when using whole-body larval N:P, and a "body" N:P of 19.77 when using allocated N:P. These values correspond to means for larvae $<20 \mathrm{~mm}$. For adults $(>100 \mathrm{~mm})$ we used a body N:P of 8.07. All these values were obtained from data in Fig. 1E and Fig. 6A. Initially, we set $\mathrm{GGE}_{\max }$ for $\mathrm{P}$ to 0.71 (Fig. 6B), the value estimated by Torres and Vanni (2007) for adult gizzard shad, based on data from several fish species as presented in Schindler and Eby (1997). Under this scenario, the model predicted recycled N:P ratios very similar to the ones observed in the field for both larvae and adults, but for larvae, allocated N:P was a better predictor than whole body N:P (Fig. 6B). Observed excretion N:P of larvae was relatively variable, compared to that of adults (Fig. 6B); therefore we varied $\mathrm{GGE}_{\max }$ to encompass this variability $(95 \%$ confidence interval for $\mathrm{N}: \mathrm{P}$ excretion ratio $=29-41)$. The predicted larval excretion N:P ratio varied between 29 and 41 when the 

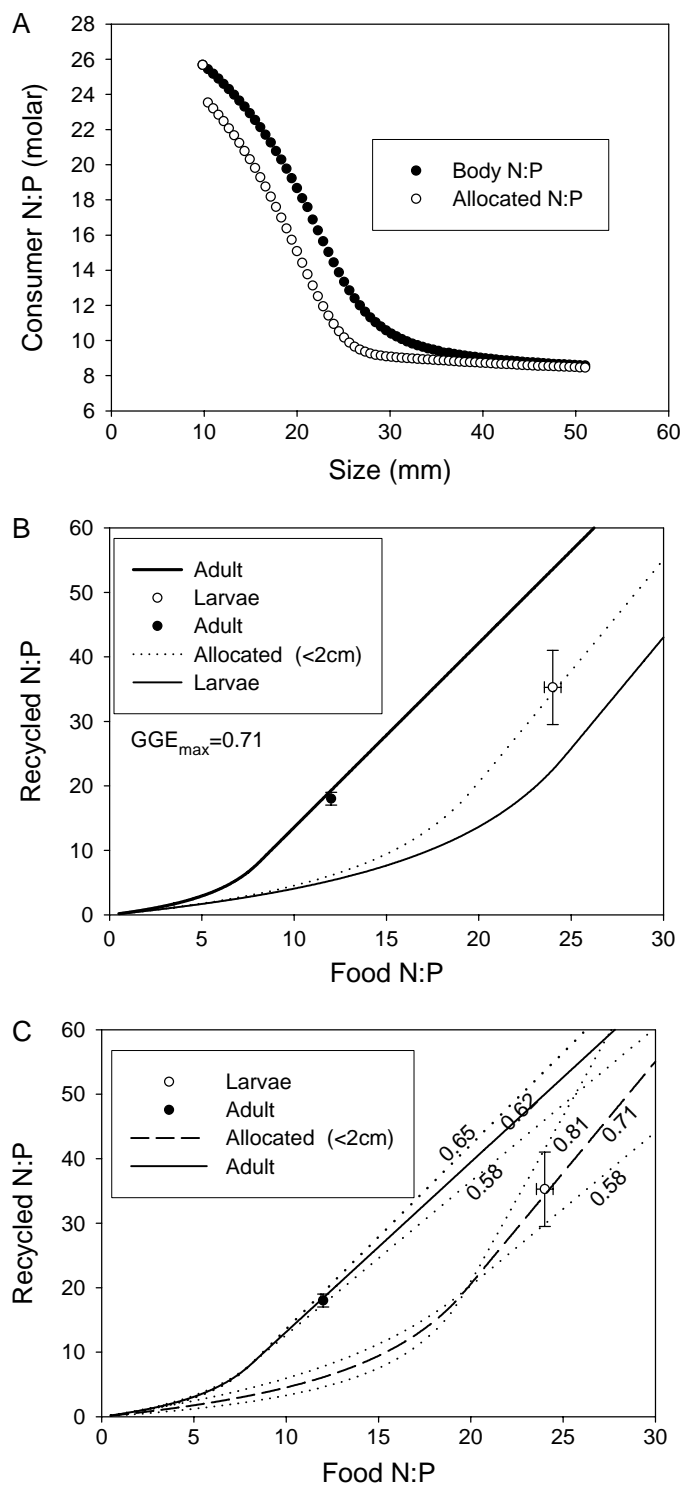

Fig. 6. (A) Consumer N:P (molar) of gizzard shad larvae and early juveniles (closed circles) and N:P allocated to new growth (open circles). (B) The Sterner model (1990) applied to adult (thick line) and larval gizzard shad when $\mathrm{GGE}_{\max }$ was held at 0.71 . Larval N:P was divided in whole-body N:P (thin line) and $\mathrm{N}: \mathrm{P}$ allocated to new growth (dotted line). (C) $\mathrm{GGE}_{\max }$ was adjusted so the estimated excreted N:P ratio coincides with the ratio observed in field experiments. The dotted lines represent the results of the model when $\mathrm{GGE}_{\max }$ was adjusted so that the model fits the $95 \%$ confidence interval of the observed excreted N:P ratio. The open circle and the closed circle represent the recycled N:P of larvae and adults respectively Error bars represent the observed SE for either recycled or food N:P.

$\mathrm{GGE}_{\max }$ ranged from 0.58 to 0.81 (Fig. 6C). Thus, a wide range of $\mathrm{GGE}_{\max }$ values are possible. Also, the predicted larval excretion N:P ratio varied between 29 and 41 when $\mathrm{GGE}_{\max }$ was kept at 0.71 and the food $\mathrm{N}: \mathrm{P}$ ratio varied between 23 and 26, which corresponds to the N:P ratio of rotifers (Jensen and Verschoor 2004) and copepods (Sterner and Elser 2002), the main food items of larval shad in Acton Lake (Paul 2000). Larval gizzard shad are known to feed on a variety of zooplankton and the particular taxa consumed varies considerably among individuals (M. Gonzalez unpubl.), as is often the case for fish. Copepods have a high N:P ratio $(>26)$, while rotifers have a lower ratio $(\sim 23)$. Therefore, depending on the food item ingested, the $\mathrm{N}: \mathrm{P}$ of the excreta would change accordingly. When larval shad (high body N:P) feed on copepods (high $\mathrm{N}: \mathrm{P}$ food) they would excrete at a higher $\mathrm{N}: \mathrm{P}$ ratio than when feeding on lower N:P items (i.e. rotifers). This shows the strong effect on diet on the excreted N:P ratio. Juveniles and adults on the other hand, apparently have a less variable N:P excretion. In order for the model to predict excreted N:P ratios similar to the ones observed in the field $(17-19,95 \% \mathrm{CI})$ the $\mathrm{GGE}_{\max }$ need to vary from 0.58 to 0.65 or the N:P of the food needs to vary from 11 to 12 (while keeping $\mathrm{GGE}_{\max }$ at 0.62 ). These values of $\mathrm{N}: \mathrm{P}$ of sediments correspond to the ones observed by Higgins et al. (2006) for ingested detritus. Although sediment detritus is a heterogeneous food resource, detritivorous shad selectively feed on detritus that is enriched in nutrients and carbon (Mundahl and Wissing 1987, Higgins et al. 2006), and excretion N:P of detritivorous shad is relatively constant, even among lakes that differ greatly in productivity (Higgins et al. 2006).

In conclusion, body $\mathrm{P}$ content was not constant along the life cycle, affecting the body $\mathrm{N}: \mathrm{P}$ and $\mathrm{C}: \mathrm{P}$ ratios of larval and juvenile stages. Furthermore these changes in $\mathrm{P}$ content and body nutrient ratios occurred regardless of the presence or absence of diet shifts. When ontogenetic $\mathrm{P}$ changes are considered within a particular species, intraspecific variation assumes a greater importance, relative to interspecific differences, than previously believed. Nevertheless, adult stages have a more stable stoichiometry. This $\mathrm{P}$ variation in all stages seems to be related to bone formation. The excretion N:P of gizzard shad is also variable along the life cycle, and, given mass balance constraints, seems to be strongly affected by food N:P. Ontogenetic variation in excretion N:P could mediate the effect of nutrient recycling on other biotic components. For example, larval excretion N:P would increase P limitation in algae while juvenile or adult excretion N:P (lower than the Redfield ratio) would increase $\mathrm{N}$ limitation. In the particular case of Acton Lake, algae are P-limited during spring and summer (when larvae are very abundant), but can become $\mathrm{N}$-limited during the fall during very dry periods (Vanni et al. 2006b) when gizzard shad YOY are $>40 \mathrm{~mm}$ and their excretion N:P decreases sharply. On the other hand, adults would alleviate the 
P-limitation that occurs during spring and summer months. This effect might be of particular interest in eutrophic lakes and reservoirs, as shad recycling can support higher proportions of algal primary productivity (Vanni et al. 2006a). More generally, these ontogenetic shifts in excretion N:P suggest that population dynamics (birth and recruitment rates, growth rates, age structure) can potentially have large effects on the limiting nutrient for primary producers.

Acknowledgements - We are grateful to the Dept of Zoology, Miami Univ., and to NSF grant DEB 0235755 for financial support for this project, Annie Bowling for nutrient analysis, and all Vanni Lab members for help in the field.

\section{References}

Bouchard, S. S. and Bjorndal, K. A. 2006. Ontogenetic diet shifts and digestive constraints in the omnivorous freshwater turtle Trachemys scripta. - Physiol. Biochem. Zool. 79: $150-158$.

Bremigan, M. T. and Stein, R. A. 1999. Larval gizzard shad success, juvenile effects, and reservoir productivity: Toward a framework for multi-system management. - Trans. Am. Fish. Soc. 128: 1106-1124.

Davis, J. A. and Boyd, C. E. 1978. Concentrations of selected elements and ash in bluegill (Lepomis machrochirus) and certain other freshwater fish. - Trans. Am. Fish. Soc. 107: $862-867$.

Deegan, L. A. 1986. Changes in body composition and morphology of young-of-the-year gulf menhaden, Brevoortia patronus Goode, in Fourleague Bay, Louisiana. - J. Fish. Biol. 29: 403-415.

DeMott, W. R. and Pape, B. J. 2005. Stoichiometry in an ecological context: testing for links between Daphnia Pcontent, growth rate and habitat preference. 2005. - Oecologia 142: 20-27.

DeMott, W. R. et al. 1998. Effect of phosphorus-deficient diets on the carbon and phosphorus balance of Daphnia magna. - Limnol. Oceanogr. 43: 1147-1161.

DeMott, W. R. et al. 2004. Patterns and sources of variation in Daphnia phosphorus content in nature. - Aquat. Ecol. 38: $433-440$.

Dettmers, J. M. and Stein, R. A. 1992. Food consumption by larval gizzard shad: zooplankton effects and its implications for reservoir communities. - Trans. Am. Fish. Soc. 121: 494-507.

Elser, J. J. and Urabe, J. 1999. The stoichiometry of consumer-driven nutrient recycling: theory, observations and consequences. - Ecology 80: 735-751.

Elser, J. J. et al. 1996. Organism size, life history, and N:P stoichiometry. Toward a unified view of cellular and ecosystem processes. - Bioscience 46: 674-684.

Elser, J. J. et al. 2000. Biological stoichiometry: from genes to ecosystems. - Ecol. Lett. 3: 540-550.

Frost, P. C. and Elser, J. J. 2002. Growth responses of littoral mayflies to the phosphorus content of their food. - Ecol. Lett. 5: 232-240.
Goodyear, C. P. and Boyd, C. E. 1972. Elemental composition of large-mouth bass (Micropterus salmoides). - Trans. Am. Fish. Soc. 3: 545-547.

Hanson, P. C. et al. 1997. Fish bioenergetics 3.0. A generalized bioenergetics model of fish growth for microcomputers. - Sea Grant Inst, Univ. of Wisconsin.

Hessen, D. O. 1990. Carbon, nitrogen and phosphorus status in Daphnia at varying food conditions. - J. Plankton Res. 12: 1239-1249.

Hessen, D. O. and Lyche, A. 1991. Inter- and intraspecific variations in zooplankton element composition. - Arch. Hydrobiol. 121: 343-353.

Higgins, K. A. et al. 2006. Detritivory and the stoichiometry of nutrient cycling by a dominant fish species in lakes of varying productivity. - Oikos 114: 419-430.

Jensen, T. C. and Verschoor, A. M. 2004. Effects of food quality on life history of the rotifer Brachionus calyciflorus Pallas. - Freshwater Biol. 49: 1138-1151.

Kraft, C. E. 1992. Estimates of phosphorus and nitrogen cycling by fish using a bioenergetics approach. - Can. J. Fish. Aquat. Sci. 49: 2596-2604.

Love, R. M. 1980. The chemical biology of fishes. Vol. 2: Advances 1968-1977. With a supplementary key to the chemical literature. - Academic Press, pp. 400.

Matthews, M. B. et al. 2002. A virtual tour of the guide for zebrafish users. - Lab Animal 31: 34-40.

Mundahl, N. D. and Wissing, T. E. 1987. Nutritional importance of detritivory in the growth and condition of gizzard shad in an Ohio reservoir. - Environ. Biol. Fish. 20: $129-142$.

Mundahl, N. D. and Wissing, T. E. 1988. Selection and digestive efficiencies of gizzard shad feeding on natural detritus and two laboratory diets. - Trans. Am. Fish. Soc. 117: $480-487$.

Paul, D. W. 2000. Effects of prey availability on larval gizzard shad prey selectivity in an Ohio reservoir. MSc thesis. - Wright State Univ., Dayton, Ohio.

Penczak, T. 1985. Phosphorus, nitrogen, and carbon cycling by fish populations in two small lowland rivers in Poland. - Hydrobiologia 120: 159-165.

Penczak, T. et al. 1985. Factors affecting nutrient budget in lakes of the R. Jorka watershed (Masurian Lakeland, Poland). VII. Input and removal of nutrients with fish. - Ekol. Pol. 33: 301-309.

Pierce, R. J. et al. 1980. Energy storage and utilization patterns of gizzard shad in Acton Lake, Ohio. - Trans. Am. Fish. Soc. 109: 611-616.

Post, D. M. 2002. Using stable isotopes to estimate trophic position: models, methods, and assumptions. - Ecology 83: 703-718.

Schaus, M. H. 1998. Effects of gizzard shad on nutrient cycles and phytoplankton in a reservoir ecosystem: roles of diet, biomass and population size-structure. $\mathrm{PhD}$ thesis. - Miami Univ., Oxford, Ohio.

Schaus, M. H. et al. 1997. Nitrogen and phosphorus excretion by detritivorous gizzard shad in a reservoir ecosystem. - Limnol. Oceanogr. 42: 1386-1397.

Schaus, M. H. et al. 2002. Biomass-dependent diet shifts in omnivorous gizzard shad: implications for growth, food web, and ecosystem effects. - Trans. Am. Fish. Soc. 131: $40-54$. 
Schindler, D. E. and Eby, L. A. 1997. Stoichiometry of fishes and their prey: implications for nutrient recycling. - Ecology 78: 1816-1831.

Shepherd, W. C. and Mills, E. L. 1996. Diel feeding, daily food intake, and Daphnia consumption by age- 0 gizzard shad in Oneida Lake, New York. - Trans. Am. Fish. Soc. 125: 411-421.

Smoot, J. C. 1999. A field study of sedimentary microbiota as food for detritivorous gizzard shad, Dorosoma cepedianum, in Acton Lake: A biomarker approach. PhD thesis. - Miami Univ., Oxford, Ohio.

Sterner, R. W. 1990. The ratio of nitrogen to phosphorus resupplied by herbivores: zooplankton and the algal competitive arena. - Am. Nat. 136: 209-229.

Sterner, R. W. and George, N. B. 2000. Carbon, nitrogen and phosphorus stoichiometry of cyprinid fishes. - Ecology 81: $127-140$

Sterner, R. W. and Elser, J. J. 2002. Ecological stoichiometry: the biology of elements from molecules to the biosphere. - Princeton Univ. Press.

Tanner, D. K. et al. 2000. Factors influencing carbon, nitrogen, and phosphorus content of fish from Lake Superior coastal wetland. - Can. J. Fish Aquat. Sci. 57: 1243-1251.

Torres, L. E. and Vanni, M. J. 2007. Stoichiometry of nutrient excretion by fish: interspecific variation in a hypereutrophic lake. - Oikos 116: 259-270.
Vanni, M. J. 2002. Nutrient cycling by animals in freshwater ecosystems. - Annu. Rev. Ecol. Syst. 33: 341-370.

Vanni, M. J. et al. 2002. Stoichiometry of nutrient cycling by vertebrates in a tropical stream: linking species identity and ecosystem processes. - Ecol. Lett. 5: 285-293.

Vanni, M. J. et al. 2005. Linking landscapes and food webs: effects of omnivorous fish and watersheds on reservoir ecosystems. - BioScience 55: 155-167.

Vanni, M. J. et al. 2006a. Nutrient cycling by fish supports relatively more primary production as lake productivity increases. - Ecology 87: 1696-1709.

Vanni, M. J. et al. 2006b. Nutrient and light limitation of reservoir phytoplankton in relation to storm-mediated pulses in stream discharge. - Arch. Hydrobiol. 167: 421445 .

Villar-Argaiz, M. et al. 2000. Life history implications of calanoid Mixodiaptomus laciniatus in C:N:P stoichiometry. - Verh. Int. Verein. Limnol. 27: 527-531.

Westerfield, M. 2000. The zebrafish book. A guide for the laboratory use of zebrafish (Danio rerio) (4th ed.). - Univ. of Oregon Press, Eugene.

Yako, L. A. et al. 1996. Feeding preferences of omnivorous gizzard shad as influenced by fish size and zooplankton density. - Trans. Am. Fish. Soc. 125: 753-759. 